\title{
Neuropatía isquémica en un paciente sometido a liposucción abdominal
}

\author{
Germán Alberto Hernández ${ }^{1}$, Pedro Luis CÁrdenas ${ }^{2}$
}

\section{Resumen}

Se describe el caso de una paciente que fue sometida a un procedimiento de liposucción abdominal y presentó un episodio agudo de pérdida visual unilateral, sin otra sintomatología. Se hizo el diagnóstico de neuropatía óptica isquémica anterior aguda por los hallazgos clínicos y angiografía con fluoresceína.

Se describen las características de esta enfermedad y se revisa la literatura en cuanto a su asociación con procedimientos quirúrgicos en general. La importancia del caso radica en su asociación a procedimientos estéticos, pues la neuropatía isquémica no es una entidad exótica como tal.

Palabras clave: neuropatía óptica isquémica, angiografía con fluoresceína.

\section{Title:}

Ischemic neuropathy related to abdominal liposuction

\begin{abstract}
We describe a case of abdominal liposuction with unilateral visual loss post surgery, without simtoms. The Angiogram image diagnostic confirm optic ischemic neuropathy.

The review include characteristics and treatment of this unfrecuent pathology. Ischemic neuropathy is not a rare disease, and association with esthetic procedures is important.
\end{abstract}

Key words: optic ischemic neuropathy, angiogram.

1 Oftalmólogo oculoplástico, Fundación Oftalmológica de Santander.

2 Neurooftalmólogo, Servicio de Neurooftalmología, Fundación Oftalmológica de Santander. Bucaramanga, Colombia. 


\section{Introducción}

La pérdida visual aguda, parcial o total, es una complicación poco frecuente en pacientes sometidos a procedimientos estéticos en general. Se han comunicado casos esporádicos en la literatura, fundamentalmente en procedimientos oftalmológicos y en procedimientos neurológicos, a pesar de existir otros factores asociados a pacientes con diagnóstico de neuropatía óptica isquémica y sometidos a liposucción. Lo relevante de este reporte es la importancia del examen del fondo de ojo y del estudio de enfermedades que puedan producir una anemia seria o hipotensión en la evaluación preoperatoria[1].

\section{Caso clínico}

Se trata de una paciente de 31 años de edad que fue sometida a liposucción abdominal cuatro días antes. Presentó astenia, adinamia y palidez mucocutánea. Consultó a oftalmología por la pérdida súbita de la agudeza visual por el ojo izquierdo. En el cuadro hemático se encontró hemoglobina de $8,8 \mathrm{mg} / \mathrm{dl}$.

En el examen oftalmológico se encontró una agudeza visual de 20/25 en el ojo derecho y de 20/400 en el izquierdo; la presión intraocular era de $12 \mathrm{~mm}$ de $\mathrm{Hg}$ en ambos ojos; el segmento anterior estaba sano y presentaba un defecto pupilar aferente de $3+/ 4$ en el ojo izquierdo. En el fondo del ojo se encontró un pulso venoso espontáneo positivo en ambos ojos y un nervio óptico con bordes borrados en el izquierdo[1, 2]. Se hizo una impresión diagnóstica de neuropatía óptica isquémica secundaria a síndrome anémico.

Se solicitó un cuadro hemático de control, velocidad de sedimentación globular y glucemia en ayunas, para descartar posibles diagnósticos diferenciales; además, fluoroangiografía retiniana de ambos ojos[3].

Se inició tratamiento empírico por vía oral, con una tableta de $30 \mathrm{mg}$ de nimodipino cada 12 horas, una tableta de $100 \mathrm{mg}$ de ácido acetilsalicílico al día y $50 \mathrm{mg}$ diarios de meticortén.

En la consulta de control, se encontró: glicemia y velocidad de sedimentación globular, normales; hemoglobina de $5,4 \mathrm{mg} / \mathrm{dl}$ y hematocrito de $16,5 \mathrm{mg} / \mathrm{dl}$, lo que confirmaba la impresión diagnóstica. Se decidió adicionar deflazacort a razón de $30 \mathrm{mg}$ por 15 días.

La fluoroangiografía fue normal en el ojo derecho; en el izquierdo, se observó palidez y bordes papilares borrosos, con importante tortuosidad vascular en la foto a color y, en la angiografía, tortuosidad vascular, borrosidad de los bordes con aumento de la fluorescencia del disco y levantamiento del mismo por un edema grave de papila. 
Se controló paciente a los 8 días de la primera consulta y se observó mejoría de la agudeza visual por el ojo afectado: 20/40 sin corrección. Se encontró un defecto pupilar aferente de $2+/ 4$ por el ojo izquierdo y disminución subjetiva del papiledema, por lo cual se decidió reducir progresivamente el tratamiento con corticoesteroides y hacer valoración por optometría. (Figura 1).

\section{Discusión}

La neuropatía óptica isquémica es la neuropatía óptica más frecuente en pacientes mayores de 50 años. Según el segmento del nervio óptico comprometido, se puede clasificar como neuropatía óptica isquémica anterior o posterior. La variedad anterior corresponde al 90\%. A su vez, esta enfermedad puede clasificarse en
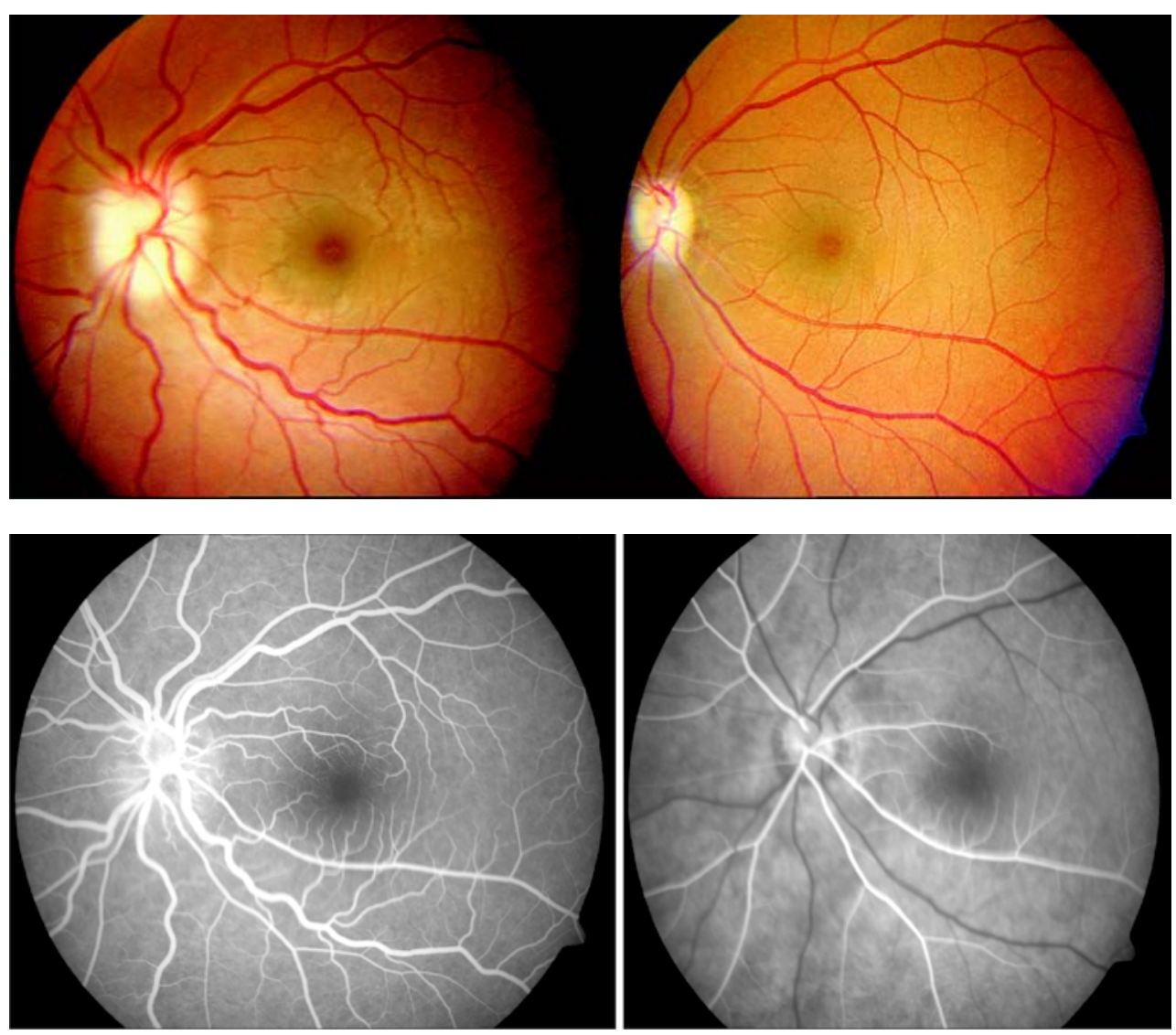

Figura 1. Fluoroangiografías del ojo afectado. En las imágenes de la izquierda, se observa borrosidad de los bordes del nervio óptico e ingurgitación vascular, en el episodio agudo.

En las imágenes de la derecha, se muestra resolución, con recuperación del calibre vascular de las arterias retinianas y apariencia normal del nervio óptico. 
vasculítica o no vasculítica, según su etiología[4].

La cabeza del nervio óptico está irrigada por ramas del anillo arterial de Zinn-Haller, formado por la unión de las arterias ciliares posteriores cortas en su porción laminar. La porción prelaminar del nervio óptico está irrigada principalmente por ramas terminales de la circulación coroidea y la porción retrolaminar está irrigada por ramas de las arterias piales[5].

La primera manifestación clínica es la pérdida visual subaguda en el transcurso de horas a semanas. En el examen oftalmoscópico se encuentra edema del disco y ausencia de pulso venoso espontáneo. La relación entre copa y disco es un parámetro objetivo para diferenciar un disco en riesgo de presentar una neuropatía óptica isquémica. Esta relación debe ser de $0,4 \mathrm{~mm}$. Un verdadero disco en riesgo tiene una relación entre copa y disco de 0,1 ó menor. Esta relación se observa como ausencia de excavación fisiológica[6].

Además de sospechar un disco en riesgo, tenemos como principales factores de riesgo a la hipertensión arterial, presente en $47 \%$ de los pacientes, y la diabetes mellitus, presente en $24 \%$. Otros factores de riesgo de menor importancia son: hipercolesterolemia, hipotensión nocturna, tabaquismo y estados protrombóticos. En último lugar están los efectos secundarios de algunos medicamentos vasoactivos, como la epinefrina administrada como descongestionante, y el sildenafilo[7].

En cuanto al tratamiento de la neuropatía óptica isquémica, no hay consenso. Puede ir desde la observación hasta el inicio de un ciclo de corticoesteroides por vía oral acompañado de nimodipino en dosis de $60 \mathrm{mg}$ al día y ácido acetilsalicílico en dosis de 100 mg al día[8].

\section{Conclusión}

Teniendo en cuenta que no existe un tratamiento efectivo para esta entidad, de acuerdo con los factores de riesgo conocidos y recordando que la edad no excluye la posibilidad de presentar la enfermedad, la prevención es el mejor abordaje del tema. En la valoración preanestésica, se deben tener en cuenta los hallazgos del oftalmólogo en la fundoscopia, como signos de retinopatía hipertensiva y ausencia de excavación fisiológica. Esto permite tomar medidas durante el acto anestésico, encaminadas a prevenir la hipotensión, la anemia por cualquier causa, la hipoxia y los estados de hipercoagulabilidad, y evitar la utilización de medicamentos vasoactivos, principalmente vasoconstrictores. 


\section{Bibliografía}

1. Cuxart M, Mates M, Picazo M, Sans R, Juvaret J, Osuna T. Pérdida visual bilateral aguda en un paciente en hemodiálisis. Nefrología. 2005;25: 703-5.

2. González AO, Mendoza CE, Santiesteban R, Francisio M. Neuropatía óptica isquémica. Instituto de Neurología y Neurocirugía. Revista Cubana de Oftalmología, 2001;30:80-3.

3. Rucker JC, Blousse V, Newman J. Ischemic optic neuropathies. Curr Opin Neurol. 2005;17:25-35.

4. Cohen AB, Pless M. Optic neuropathy with disc edema. Learning Neurol. 2009;15:22-46.
5. Muñoz JA, Serrano J, Cossio A, Serrano E, Hernández JG. Manifestaciones oftalmológicas en la enfermedad carotídea. Angiología. 2006;34:56-62.

6. Jost B, Liang X. Optic disc morphology in eyes after nonarteritic anterior ischemic optic neuropathy. Invest Ophtalmol Vis Sci. 1998;34:2260-5.

7. Sánchez A. Neuropatía óptica posterior. Hospital General de Insalud. Sociedad Española de Oftalmología. 2009.

8. Prado A, de Obaldia I, Moreno M. Neuropatía óptica asociada a migraña. Rev Mex Oftalmol. 2004;78:250-6. 